\title{
Article \\ Control of Low-Density Lipoprotein Cholesterol in Secondary Prevention of Coronary Artery Disease in Real-Life Practice: The DAUSSET Study in French Cardiologists
}

\author{
Jean Ferrières ${ }^{1, *(\mathbb{D}}$, François Roubille ${ }^{2} \mathbb{D}$, Michel Farnier ${ }^{3}$, Patrick Jourdain $4 \mathbb{D}^{\mathbb{D}}$, Denis Angoulvant ${ }^{5}(\mathbb{D}$, \\ Franck Boccara ${ }^{6}$ a and Nicolas Danchin ${ }^{7}$
}

check for

updates

Citation: Ferrières, J.; Roubille, F.; Farnier, M.; Jourdain, P.; Angoulvant,

D.; Boccara, F.; Danchin, N. Control of Low-Density Lipoprotein Cholesterol in Secondary Prevention of Coronary Artery Disease in Real-Life Practice: The DAUSSET Study in French Cardiologists. J. Clin. Med. 2021, 10, 5938. https://doi.org/10.3390/ jcm10245938

Academic Editor: Taishi Yonetsu

Received: 9 November 2021

Accepted: 13 December 2021

Published: 17 December 2021

Publisher's Note: MDPI stays neutral with regard to jurisdictional claims in published maps and institutional affiliations.

Copyright: (C) 2021 by the authors Licensee MDPI, Basel, Switzerland. This article is an open access article distributed under the terms and conditions of the Creative Commons Attribution (CC BY) license (https:/ / creativecommons.org/licenses/by/ $4.0 /)$.
1 Department of Cardiology, Toulouse Rangueil University Hospital, INSERM UMR 1295, Toulouse University School of Medicine, 31059 Toulouse, France

2 PhyMedExp, INSERM, CNRS, Cardiology Department, INI-CRT, CHU de Montpellier, Université de Montpellier, 34090 Montpellier, France; francois.roubille@gmail.com

3 Equipe PEC2, EA 7460, Service de Cardiologie, CHU Dijon Bourgogne, Université de Bourgogne Franche-Comté, 21000 Dijon, France; farnier.michel@orange.fr

4 CHU Bicêtre AP-HP, Inserm U999, Université Paris-Saclay, 91190 Gif-sur-Yvette, France; patrick.jourdain@aphp.fr

5 Service de Cardiologie, Hôpital Trousseau, CHRU de Tours, EA4245 T2i Faculté de médecine et Université de Tours, 37000 Tours, France; denis.angoulvant@univ-tours.fr

$6 \mathrm{GRC} \mathrm{n}^{\circ} 22, \mathrm{C}^{2} \mathrm{MV}$-Complications Cardiovasculaires et Métaboliques chez les Patients Vivant avec le Virus de L'immunodéficience Humaine, INSERM UMR_S 938, Centre de Recherche Saint-Antoine, Institut Hospitalo-Universitaire de Cardio-métabolisme et Nutrition (ICAN), Hôpital Saint-Antoine Service de Cardiologie, Assistance Publique-Hôpitaux de Paris, Sorbonne Université, 75012 Paris, France; franck.boccara@aphp.fr

7 Département de Cardiologie, Hôpital Européen Georges Pompidou et Université de Paris, 75015 Paris, France; nicolasdanchin@yahoo.fr

* Correspondence: jean.ferrieres@univ-tlse3.fr

Abstract: Introduction: Patients with established coronary artery disease (CAD) are at very high risk for cardiovascular events. Methods: The DAUSSET study is a national, multicenter, noninterventional study that included very high-risk CAD patients followed by French cardiologists. It aimed to describe real-life clinical practices for low-density lipoprotein (LDL) cholesterol control in the secondary prevention of CAD. Results: A total of 912 patients (mean age, 65.4 years; men, $76.1 \%$; myocardial infarction, $69.4 \%$; first episode, $80.1 \%$ ) were analyzed. The LDL cholesterol goal was $70 \mathrm{mg} / \mathrm{dL}$ in most cases (84.9\%). The LDL cholesterol goal $<70 \mathrm{mg} / \mathrm{dL}$ was achieved in $41.7 \%$ of patients. Of the 894 (98.0\%) patients who received lipid-lowering therapy, $81.2 \%$ had been treated more intensively after the cardiac event, $27.0 \%$ had been treated less intensively and $13.1 \%$ had been maintained. Participating cardiologists were very satisfied or satisfied with treatment response in $72.6 \%$ of patients. Moderate satisfaction or dissatisfaction with lipid-lowering therapy was related to not achieving objectives (100\%), treatment inefficacy $(53.7 \%)$, treatment intolerance $(23.4 \%)$ and poor adherence (12.3\%). Conclusion: These real-world results show that lipid control in very high-risk patients remains insufficient. More than half of the patients did not achieve the LDL cholesterol goal. Prevention of cardiovascular events in these very high-risk patients could be further improved by better education and more intensive lipid-lowering therapy.

Keywords: dyslipidemia; hypercholesterolemia; coronary artery disease; myocardial infarction; secondary prevention; guidelines adherence

\section{Introduction}

Large epidemiological studies have shown a close and direct relationship between blood lipid levels and the risk of coronary artery disease (CAD) and stroke [1,2]. Hypercholesterolemia is a major contributor to the development of CAD and high levels 
of low-density lipoprotein cholesterol (LDL-C) are associated with an increased risk of CAD [3]. In a meta-analysis of 90,056 patients from 14 randomized statin trials, a $39 \mathrm{mg} / \mathrm{dL}$ $(1 \mathrm{mmol} / \mathrm{L})$ decrease in LDL-C levels in patients with CAD reduced the 5-year rate of major vascular events by approximately one fifth [4].

As a result, reducing levels of LDL-C has become a major objective of guidelines for the treatment and secondary prevention of atherosclerotic cardiovascular disease [2,5-8]. In patients at very high cardiovascular risk, the goal defined by the 2016 European guidelines was an LDL-C level $<70 \mathrm{mg} / \mathrm{dL}(1.8 \mathrm{mmol} / \mathrm{L})$ or at least a $50 \%$ reduction if the reference value was between 70 and $135 \mathrm{mg} / \mathrm{dL}$ [5]. In the 2019 ESC/EAS dyslipidemia guidelines, a target of $55 \mathrm{mg} / \mathrm{dL}$ LDL-C is recommended for all patients with very high-risk criteria and $40 \mathrm{mg} / \mathrm{dL}$ for patients with a second vascular event within 2 years [7].

Despite these recommendations, real-world studies have shown that only a small percentage of high-risk patients achieved lipid goals. For example, the EUROASPIRE IV survey conducted in 24 European countries showed that only $19.5 \%$ of patients with CAD had LDL-C levels $<70 \mathrm{mg} / \mathrm{dL}$ [9]. In the first Dyslipidemia International Study (DYSIS), only $21.7 \%$ of very high-risk patients in European countries achieved their LDLC goal $[10,11]$. In the DYSIS II study in seven European countries, LDL-C levels were $<70 \mathrm{mg} / \mathrm{dL}$ in $28.3 \%$ of patients with stable CAD and $15.7 \%$ in patients who had been hospitalized with acute coronary syndrome (ACS) [12]. More recently, the ICLPS study in non-Western European countries outside the USA and Canada showed that only $28.5 \%$ of the very high-risk population achieved the recommended goal [13].

Cardiologists are on the forefront of treating patients. Various factors may affect the efficacy of treatment, such as poor adherence, side effects related to lipid-lowering treatment (LLT), insufficient response to treatment, drug interactions or associated comorbidities, but also factors related to the patient's lifestyle or socio-economic conditions. The present study was designed to evaluate the practices of cardiologists, in real-world conditions, in the management of LDL-C risk in patients diagnosed with CAD. The primary objective of the study was to describe the current practice of cardiologists in managing lipid risk in patients with established CAD (secondary prevention). For this purpose, we assessed the rate of patients with an established diagnosis of CAD who achieved the LDL-C goal $<70 \mathrm{mg} / \mathrm{dL}$ and the rates of treatment changes.

\section{Materials and Methods}

\subsection{Study Design}

The "observatoire national pour l'évaluation Des prAtiques des cardiologUes danS la priSe en charge du risquE lipidique en prévenTion secondaire (DAUSSET)" is a national, multicenter, non-interventional study conducted among French cardiologists. The objective of the study was to describe, in a real-life setting, the clinical practices for LDL-C risk control in secondary prevention of CAD.

The study conformed to the principles of the Declaration of Helsinki and Good Clinical Practice Guidelines. It was approved by the Ethics Committee "CPP NORD-OUEST II" (ID-RCB: 2017-A00280-53).

Investigators from a representative random sample of cardiologists in metropolitan France were asked to consecutively include patients who met the inclusion criteria.

\subsection{Patients}

Adult patients were included if they had established CAD treated for secondary prevention. The diagnosis of CAD comprised documented acute coronary syndrome: STsegment elevation myocardial infarction (STEMI), non-ST-segment elevation myocardial infarction (NSTEMI), unstable angina, silent ischemia or stable angina documented by coronary angiography (stenosis $>50 \%$ ).

Patients had to be seen by the cardiologist more than 3 months but less than 3 years after the onset of the index coronary event, defined as the last documented ACS or diagnosis of CAD (coronary stenosis $>50 \%$ in patients with stable angina or silent myocardial 
ischemia). Lipid tests performed on the following dates were recorded: before the index coronary event (diagnosis of CAD or ACS, whichever was the latest), at the time of the index coronary event (within 7 days of the event) and within 3 months before study entry. Only lipid tests at the time of the index coronary event were mandatory.

Patients with secondary dyslipidemia (uncontrolled hypothyroidism or nephrotic syndrome) and those participating in a clinical study that might alter the lipid profile (involving the use of lipid-lowering drugs) were not eligible to participate in the study.

\subsection{Study Objectives}

The primary objective of the study was to describe the current practice of cardiologists in managing lipid risk in patients with established CAD (secondary prevention).

The main secondary objectives were to describe the study population (demographics, cardiovascular risk factors) and patient care pathway; to assess the prevalence of possible familial hypercholesterolemia in the current clinical practice of cardiologists; to describe the therapeutic goals of cardiologists in managing lipid risk in the patient population (target level of LDL-C defined for the patient); to describe the therapeutic strategies employed by cardiologists in lipid risk management in secondary prevention; and to describe patient adherence to LLT.

\subsection{Data Collection}

Study data were collected by the physicians in a case report form during the visit from medical files, clinical examination and patient questioning. Patient data included sociodemographic data (age, gender, occupation, physical activity level); clinical examination at inclusion (weight, height, blood pressure, heart rate, known clinical signs suggesting familial hypercholesterolemia); personal cardiovascular risk factors (high blood pressure, known hypercholesterolemia before the event, microalbuminuria $>30 \mathrm{mg} / 24 \mathrm{~h}$, type 2 diabetes, smoking, sedentary lifestyle, rheumatoid arthritis, depression, HIV); description of the index coronary event, i.e., diagnosis of CAD or last ACS, regardless of which event occurred last; type (ST-segment elevation MI (STEMI), non-ST-segment elevation MI (NSTEMI), unstable angina, diagnosis of coronary disease for patients with stable angina or silent myocardial ischemia); territory; previous LLT; result of last available coronary angiography; revascularization procedure during ACS; acute heart failure; immediate post-ACS treatment (LLT, concomitant treatment); personal history of CAD prior to the index cardiac event; personal history of other cardiovascular disease; family history of cardiovascular disease; patient care pathway from the onset of cardiologic follow-up (referral to investigator, follow-up by investigator since the index coronary event or before cardiac rehabilitation program at the time of the index coronary event, adherence to lifestyle recommendations); therapeutic objectives set for the patient by the cardiologist (LDL-C goal); compliance and satisfaction of the physician with the response to treatment; and, if applicable, reasons for failure to achieve the therapeutic objective.

\subsection{Statistical Analysis}

The analyses were essentially descriptive, and no formal hypotheses were tested. We calculated that describing a 50\% response rate with sufficient precision (3\%) required a sample size of at least 1000 patients.

The primary endpoints were the rate of patients with an established diagnosis of CAD who achieved the LDL-C goal $<70 \mathrm{mg} / \mathrm{dL}$; the rate of patients whose treatment was stepped up (initiation of statin therapy, increase in the current statin dose, switch to a more potent statin, initiation of a new compound, e.g., ezetimibe); the rate of patients whose treatment was reduced (discontinuation or reduction of statin therapy or switch to a less potent statin therapy); and the rate of patients maintained on LLT overall.

Statistical analyses were performed using SAS software version 9.3 (SAS Institute, Inc., Cary, North Carolina, USA). 


\section{Results}

\subsection{Characteristics of Participating Cardiologists}

A total of 77 cardiologists practicing in public or private hospitals (57.1\%), with private practice $(23.4 \%)$ or with mixed practice $(19.5 \%)$ enrolled at least one patient. They were distributed throughout the national territory (46 out of the 96 French metropolitan departments). They had a median of 37 patients per month (range, 20-80) for secondary prevention.

\subsection{Patient Characteristics and Index Cardiac Event}

From July 2017 to October 2018, 1005 patients were selected, 93 of whom were not eligible. The analysis population was composed of 912 patients with a mean (SD) age of 65.4 (11.8) years; the majority were male (76.1\%) and the mean (SD) body mass index was $27.1(4.4) \mathrm{kg} / \mathrm{m} 2$ (Table 1). The main risk factors reported were treated hypertension $(49.0 \%)$, known hypercholesterolemia before the cardiac event $(46.7 \%)$, smoking $(40.7 \%)$, sedentary lifestyle $(37.7 \%)$ and type 2 diabetes $(21.5 \%)$. A family history of premature cardiovascular disease was reported in $14.3 \%$ of male and $6.1 \%$ of female family members. The most common cardiovascular history was coronary revascularization $(17.8 \%)$ and myocardial infarction (12.5\%) (Table 1).

Table 1. Characteristics of very high-risk CAD patients included in the study.

\begin{tabular}{|c|c|c|}
\hline & Number of Patients Evaluated & $\begin{array}{l}\text { Analysis Population } \\
(n=912)\end{array}$ \\
\hline Age, years, mean (SD) & 912 & $65.4(11.8)$ \\
\hline \multicolumn{3}{|l|}{ Gender, n (\%) } \\
\hline Male & 912 & $694(76.1)$ \\
\hline Female & 912 & $218(23.9)$ \\
\hline Body mass index, $\mathrm{kg} / \mathrm{m}^{2}$, mean (SD) & 889 & $27.1(4.4)$ \\
\hline Systolic blood pressure, $\mathrm{mmHg}$, mean (SD) & 898 & $133.1(17.4)$ \\
\hline Diastolic blood pressure, $\mathrm{mmHg}$, mean (SD) & 898 & $76.4(10.2)$ \\
\hline Heart rate, beats / min, mean (SD) & 889 & $66.1(11.1)$ \\
\hline Clinical signs of familial hypercholesterolemia, n (\%) & 857 & $8(0.9)$ \\
\hline \multicolumn{3}{|l|}{ Risk factors, $\mathrm{n}(\%)$} \\
\hline Treated hypertension & 912 & $447(49.0)$ \\
\hline Known hypercholesterolemia before cardiac event & 912 & $426(46.7)$ \\
\hline Smoking & 887 & $391(44.1)$ \\
\hline Sedentary lifestyle & 897 & $338(37.7)$ \\
\hline Type 2 diabetes & 912 & $196(21.5)$ \\
\hline Depressive disorder & 909 & $56(6.2)$ \\
\hline Microalbuminuria $>30 \mathrm{mg} / 24 \mathrm{~h}$ & 422 & $15(3.6)$ \\
\hline Untreated hypertension & 912 & $24(2.6)$ \\
\hline HIV infection & 863 & $15(1.7)$ \\
\hline Rheumatoid arthritis & 906 & $5(0.6)$ \\
\hline \multicolumn{3}{|l|}{ Patient cardiovascular history, n (\%) } \\
\hline Coronary revascularization & 912 & $162(17.8)$ \\
\hline Myocardial infarction & 912 & $114(12.5)$ \\
\hline Unstable angina & 912 & $67(7.3)$ \\
\hline Peripheral artery disease & 909 & $58(6.4)$ \\
\hline Ischemic stroke & 909 & $52(5.7)$ \\
\hline Stable angina & 912 & $50(5.5)$ \\
\hline Heart failure & 910 & $38(4.2)$ \\
\hline Silent myocardial infarction & 912 & $11(1.2)$ \\
\hline Hemorrhagic stroke & 910 & $2(0.2)$ \\
\hline \multicolumn{3}{|l|}{ Family history of premature cardiovascular disease, $\mathrm{n}(\%)$} \\
\hline Male & 781 & $112(14.3)$ \\
\hline Female & 781 & $48(6.1)$ \\
\hline
\end{tabular}


The index event occurred a mean (SD) of 16.8 (9.2) months prior to inclusion (Table 2). It was the first episode for $80.1 \%$ of patients. The most frequent index events were STEMI (39.6\%) and NSTEMI (29.8\%); diagnosis of coronary disease and unstable angina accounted for $16.1 \%$ and $14.5 \%$ of cases, respectively. The main locations of index events were anterior $(42.3 \%)$ and inferior (29.8\%). Patients had received prior lipid-lowering therapy in $39.4 \%$ of cases.

Table 2. Characteristics of the index cardiac event of the very high-risk CAD study patients.

\begin{tabular}{|c|c|c|}
\hline & Number of Patients Evaluated & $\begin{array}{l}\text { Analysis Population } \\
(n=912)\end{array}$ \\
\hline Age at the index event, years, mean (SD) & 912 & $64.1(11.8)$ \\
\hline Time between index event and inclusion, months, mean (SD) & 912 & $16.8(9.2)$ \\
\hline \multicolumn{3}{|l|}{ Type of occurrence, $\mathrm{n}(\%)$} \\
\hline First episode & 911 & $730(80.1)$ \\
\hline Recurrence & 911 & $181(19.9)$ \\
\hline \multicolumn{3}{|l|}{ Type of event, $\mathrm{n}(\%)$} \\
\hline ST-segment elevation myocardial infarction & 912 & $361(39.6)$ \\
\hline non-ST-segment elevation myocardial infarction & 912 & $272(29.8)$ \\
\hline Coronary disease diagnosis & 912 & $147(16.1)$ \\
\hline Unstable angina & 912 & $132(14.5)$ \\
\hline \multicolumn{3}{|l|}{ Main locations of the index event, $\mathrm{n}(\%) \mathrm{a}$} \\
\hline Anterior & 898 & $380(42.3)$ \\
\hline Inferior & 898 & $268(29.8)$ \\
\hline Lateral & 898 & $103(11.5)$ \\
\hline Previous lipid-lowering therapy, n (\%) & 884 & $348(39.4)$ \\
\hline \multicolumn{3}{|l|}{ Results of coronary angiography, n (\%) } \\
\hline Single-vessel disease & 909 & $365(40.2)$ \\
\hline Two-vessel disease & 909 & $324(35.6)$ \\
\hline Three-vessel disease & 909 & $198(21.8)$ \\
\hline Left main artery & 909 & $4(0.4)$ \\
\hline Single-vessel disease and left main artery & 909 & $1(0.1)$ \\
\hline Two-vessel disease and left main artery & 909 & $6(0.7)$ \\
\hline Three-vessel disease and left main artery & 909 & $11(1.2)$ \\
\hline \multicolumn{3}{|l|}{ Revascularization procedure, $\mathrm{n}(\%)$} \\
\hline None & 912 & $68(7.5)$ \\
\hline Angioplasty with stent & 912 & $762(83.6)$ \\
\hline Angioplasty without stent & 912 & $21(2.3)$ \\
\hline Angioplasty (no information on stent) & 912 & $2(0.2)$ \\
\hline Coronary bypass surgery & 912 & $59(6.5)$ \\
\hline Acute heart failure during acute phase, $\mathrm{n}(\%)$ & 904 & $79(8.7)$ \\
\hline Lipid-lowering therapy at discharge, $\mathrm{n}(\%)^{a}$ & 912 & $893(97.9)$ \\
\hline Low intensity & 893 & $38(4.3)$ \\
\hline Moderate intensity & 893 & $168(18.8)$ \\
\hline High intensity & 893 & $687(76.9)$ \\
\hline Associated treatment at discharge, $\mathrm{n}(\%)$ & 912 & $911(99.9)$ \\
\hline Beta blockers & 910 & $802(88.1)$ \\
\hline Renin-angiotensin system blockers & 910 & $717(78.8)$ \\
\hline Calcium channel inhibitors & 907 & $121(13.3)$ \\
\hline Nitroglycerin & 902 & $103(11.4)$ \\
\hline
\end{tabular}

a Low-intensity lipid-lowering therapy lowers LDL-C by $<30 \%$ on average, moderate intensity therapy by approximately $30 \%$ to $50 \%$ on average and high intensity therapy by approximately $\geq 50 \%$ on average.

Coronary angiography most frequently revealed single-vessel disease $(40.2 \%)$ and two-vessel disease (35.6\%) (Table 2). Most patients had undergone a percutaneous coronary intervention with stent implantation $(83.6 \%)$; there was no revascularization procedure in only $7.5 \%$ of patients.

At discharge, almost all patients received LLT (97.9\%), most frequently at high intensity $(76.9 \%)$. 


\subsection{Lipid Assessments}

Lipid assessments before the index event were reported for only a small number of patients. However, the values reported for lipid work-up before and just after the index cardiac event were comparable (Table 3 and Figure 1). From the index date to study inclusion, mean total cholesterol values improved from 191 to $157 \mathrm{mg} / \mathrm{dL}$ and mean LDL-C values from 118 to $83 \mathrm{mg} / \mathrm{dL}$. At inclusion, $22.0 \%$ of patients had LDL-C >100 mg/dL.

Table 3. Lipid assessment of very high-risk CAD patients before and after the index cardiac event.

\begin{tabular}{|c|c|c|}
\hline & Number of Patients Evaluated & $\begin{array}{l}\text { Analysis Population } \\
\qquad(n=912)\end{array}$ \\
\hline \multicolumn{3}{|l|}{ Before the index event } \\
\hline Lipid-lowering treatment, $\mathrm{n}(\%)$ & 296 & $143(48.3)$ \\
\hline Total cholesterol, mg/dL, mean (SD) & 134 & $196(55)$ \\
\hline LDL-cholesterol, mg/dL, mean (SD) & 143 & $121(48)$ \\
\hline HDL-cholesterol, mg/dL, mean (SD) & 136 & $49(19)$ \\
\hline Triglycerides, mg/dL, mean (SD) & 139 & $144(82)$ \\
\hline \multicolumn{3}{|l|}{ After the index cardiac event (within 7 days) } \\
\hline Lipid-lowering treatment at discharge, $\mathrm{n}(\%)$ & 912 & $893(97.9)$ \\
\hline Total cholesterol, mg/dL, mean (SD) & 901 & $191(55)$ \\
\hline LDL-cholesterol, mg/dL, mean (SD) & 895 & $118(047)$ \\
\hline HDL-cholesterol, mg/dL, mean (SD) & 910 & $45(16)$ \\
\hline Triglycerides, $\mathrm{mg} / \mathrm{dL}$, mean (SD) & 908 & $147(95)$ \\
\hline \multicolumn{3}{|l|}{ At study inclusion (within 3 months) } \\
\hline Lipid-lowering treatment, $\mathrm{n}(\%)$ & 912 & $894(98.0)$ \\
\hline Total cholesterol, mg/dL, mean (SD) & 689 & $157(45)$ \\
\hline LDL-cholesterol, mg/dL, mean (SD) & 695 & $83(37)$ \\
\hline LDL-cholesterol >100 mg/dL, n (\%) & 695 & $153(22.0)$ \\
\hline HDL-cholesterol, mg/dL, mean (SD) & 695 & $48(16)$ \\
\hline Triglycerides, mg/dL, mean (SD) & 689 & $131(96)$ \\
\hline
\end{tabular}

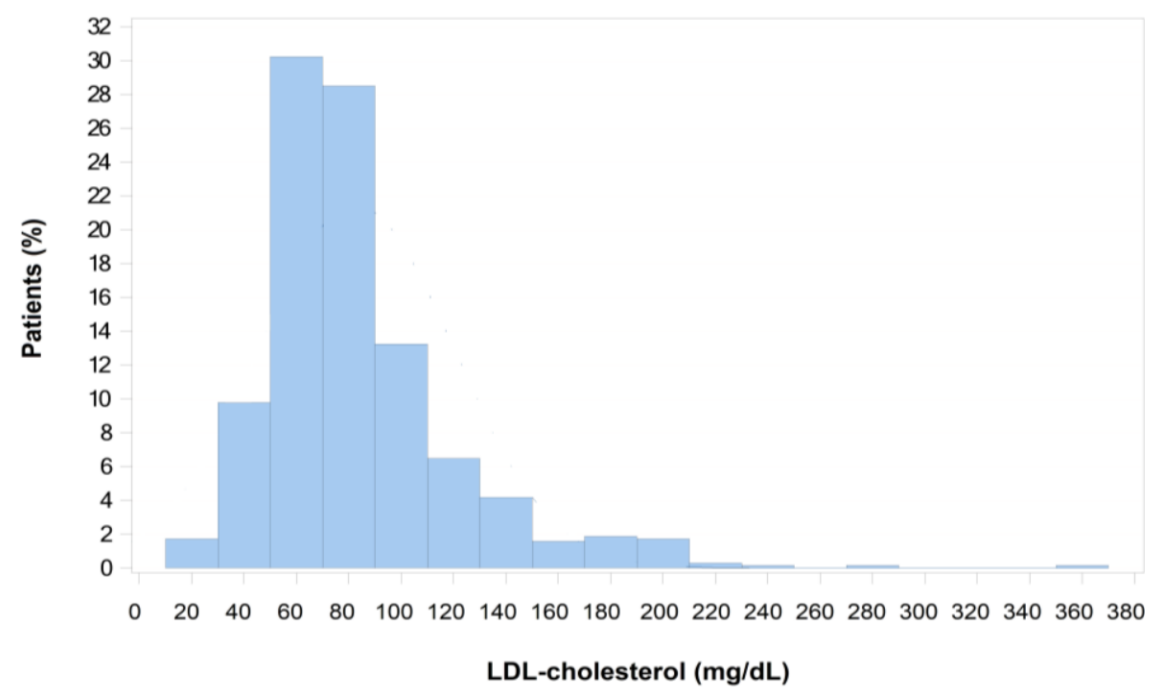

Figure 1. LDL-cholesterol at inclusion.

\subsection{Follow-Up by Cardiologist after Index Cardiac Event and LDL-C Goal}

In $66.8 \%$ of cases, participating cardiologists followed the patient before the index cardiac event for a mean (SD) duration of 8.1 (7.0) years (Table 4). Patients were referred to the participating cardiologists either directly after the cardiac event $(39.5 \%)$, by the attending physician $(36.1 \%)$ or by the hospital or clinic $(24.3 \%)$. Patients attended a cardiac rehabilitation program primarily at a rehabilitation center (80.3\%). Patients were considered adherent to a healthy lifestyle and treatment in $70.9 \%$ and $93.5 \%$ of cases, respectively. 
Table 4. Patient care after index cardiac event and LDL-C goal.

\begin{tabular}{|c|c|c|}
\hline & Number of Patients Evaluated & $\begin{array}{l}\text { Analysis Population } \\
\qquad(n=912)\end{array}$ \\
\hline Follow-up by the investigator before index cardiac event, $\mathrm{n}(\%)$ & 911 & $609(66.8)$ \\
\hline Duration of follow-up, years, mean (SD) & 302 & $8.1(7.0)$ \\
\hline \multicolumn{3}{|l|}{ Referral to participating cardiologist for the first time, $\mathrm{n}(\%)$} \\
\hline Hospital or clinic & 912 & $222(24.3)$ \\
\hline Directly after cardiac event & 912 & $360(39.5)$ \\
\hline Attending physician & 912 & $329(36.1)$ \\
\hline Other & 912 & $35(3.8)$ \\
\hline Cardiac rehabilitation program, $\mathrm{n}(\%)$ & 900 & $407(45.2)$ \\
\hline In hospital & 407 & $87(21.4)$ \\
\hline In rehabilitation center & 407 & $327(80.3)$ \\
\hline In hearth and health club & 407 & $1(0.2)$ \\
\hline Compliance with healthy lifestyle, n (\%) & 911 & $646(70.9)$ \\
\hline Compliance with treatment, $\mathrm{n}(\%)$ & 898 & $840(93.5)$ \\
\hline \multicolumn{3}{|l|}{ Target LDL-C, mg/dL, n (\%) } \\
\hline $50-70$ & 912 & $6(0.7)$ \\
\hline 70 & 912 & $774(84.9)$ \\
\hline $70-100$ & 912 & $55(6.0)$ \\
\hline 100 & 912 & $77(8.4)$ \\
\hline Target LDL-C communicated to patient, n (\%) & 908 & $799(88.0)$ \\
\hline Target LDL-C communicated to attending physician, $\mathrm{n}(\%)$ & 895 & $721(80.6)$ \\
\hline \multicolumn{3}{|l|}{ Satisfaction of cardiologist for treatment response, $\mathrm{n}(\%)$} \\
\hline Very satisfied & 890 & $381(42.8)$ \\
\hline Satisfied & 890 & $265(29.8)$ \\
\hline Moderately satisfied & 890 & $160(18.0)$ \\
\hline Not at all satisfied & 890 & $84(9.4)$ \\
\hline \multicolumn{3}{|l|}{ Reasons for moderate satisfaction/dissatisfaction, $\mathrm{n}(\%)^{\mathrm{a}}$} \\
\hline Objective not reached & 244 & $244(100)$ \\
\hline Treatment inefficacy & 244 & $131(53.7)$ \\
\hline Treatment intolerance & 244 & $57(23.4)$ \\
\hline Poor treatment compliance & 244 & $30(12.3)$ \\
\hline Treatment refusal & 244 & $6(2.5)$ \\
\hline Rare dyslipidemia & 244 & $1(0.4)$ \\
\hline Other reason & 244 & $48(19.7)$ \\
\hline
\end{tabular}

${ }^{\text {a }}$ More than one answer was possible.

The LDL-C goal defined by the cardiologist was $70 \mathrm{mg} / \mathrm{dL}$ in most cases $(84.9 \%)$. This goal was communicated to the patient and attending physician in $88.0 \%$ and $80.6 \%$ of cases, respectively.

The participating cardiologists were very satisfied or satisfied with the response to treatment in $72.6 \%$ of cases. When the participating cardiologists were only moderately satisfied or dissatisfied, the main reasons were: objective not reached $(100 \%)$, treatment inefficacy $(53.7 \%)$, treatment intolerance $(23.4 \%)$ and poor compliance to treatment $(12.3 \%)$.

LDL-C $<70 \mathrm{mg} / \mathrm{dL}$ was achieved in $41.7 \%$ of patients at inclusion. Of the $894(98.0 \%)$ patients with LLT, treatment had been intensified in $81.2 \%$, decreased in $27.0 \%$ and maintained in $13.1 \%$ since the index cardiac event (Table 5).

Achievement of the LDL-C goal was higher when the duration from the index event was $\leq 12$ months (45.5\%; 90/308) compared with $>12$ months (40.2\%; 200/497).

Subgroup analyses indicated that LLT after the index cardiac event was more frequently intensified $(95.3 \%)$ and LDL-C $<70 \mathrm{mg} / \mathrm{dL}$ was more frequently achieved (45.4\%) in patients without LLT before the index cardiac event; these percentages were $35.7 \%$ and $59.6 \%$ in patients with LLT before the index cardiac event, respectively. 
Table 5. Primary endpoints: achievement of target LDL-C $<70 \mathrm{mg} / \mathrm{dL}$ and changes in lipid-lowering treatment.

\begin{tabular}{ccc}
\hline & Number of Patients Evaluated & $\begin{array}{c}\text { Analysis Population } \\
(\boldsymbol{n}=\mathbf{9 1 2})\end{array}$ \\
\hline LDL-C target achieved $(<70 \mathrm{mg} / \mathrm{dL}), \mathrm{n}(\%)$ & 695 & $290(41.7)$ \\
Patients with lipid-lowering treatment, n (\%) ${ }^{a}$ & 912 & $894(98.0)$ \\
Therapy intensification & 894 & $726(81.2)$ \\
Decrease in therapy & 891 & $241(27.0)$ \\
Lipid-lowering treatment maintained & 894 & $117(13.1)$ \\
Patients with no lipid-lowering treatment, $\mathrm{n}(\%)$ & 912 & $18(2.0)$ \\
\hline
\end{tabular}

a Patients could be counted both in "therapy intensification" class and in "decrease in therapy" class; patients in the "lipid-lowering treatment maintained" class were counted only once.

\section{Discussion}

The characteristics of the study patients with established CAD, treated for secondary prevention and therefore at very high cardiovascular risk, were as expected (mean age, 65.4 years; men, $76.1 \%$; myocardial infarction, $69.4 \%$; history of hypertension, $49.0 \%$; hypercholesterolemia, $46.7 \%$; type II diabetes, $21.5 \%$ ). Clinical signs of familial hypercholesterolemia were observed in $0.9 \%$ of patients. Comparable patient characteristics were reported in French patients with ACS in the DYSIS II study performed in 2013-2014 [14].

Patients received LLT at discharge in $97.9 \%$ of cases, most often at high intensity (76.9\%); at inclusion in the study, $98.0 \%$ of patients were on LLT. At follow-up, therapy had been intensified in $81.2 \%$ of patients since the cardiovascular event. These data suggest that cardiologists followed guidelines and recommendations by prescribing higher doses of statins in very high-risk patients [5]. Indeed, in addition to lifestyle modifications, prescribing a statin at the highest recommended dose or the highest tolerable dose to achieve the LDL-C goal is the first choice [6,7]. Ezetimibe is recommended for patients who are intolerant to statins or who do not achieve LDL-C goal with statin monotherapy [6,7].

The LDL-C goal was set by the cardiologist at $70 \mathrm{mg} / \mathrm{dL}$ for $84.9 \%$ of patients and at $70-100 \mathrm{mg} / \mathrm{dL}$ for $14.4 \%$. According to the $2016 \mathrm{ESC} / \mathrm{EAS}$ guidelines that were ongoing at the time of the study, an LDL-C level $<70 \mathrm{mg} / \mathrm{dL}$ or a reduction of at least $50 \%$ if the baseline value was between 70 and $135 \mathrm{mg} / \mathrm{dL}$ was recommended for patients at very high cardiovascular risk [5]. These results indicate that almost all patients had LDL-C goals set as recommended [5].

From index cardiac event to study inclusion, mean total cholesterol and LDL-C values decreased from 191 to $157 \mathrm{mg} / \mathrm{dL}$ and from 118 to $83 \mathrm{mg} / \mathrm{dL}$, respectively. An LDL-C goal of $<70 \mathrm{mg} / \mathrm{dL}$ was achieved in $41.7 \%$ of patients. These results on the achievement of the LDL-C goal can be compared with those of other studies. In the subgroup of French patients hospitalized with an ACS in the DYSIS II study, statins were used in $96.6 \%$ of patients at discharge and in $95.1 \%$ of patients at 120-day follow-up [14]. At that time, 50.6\% $(80 / 158)$ of patients with available data achieved the LDL-C goal. The longer duration from index cardiovascular event to inclusion ( $16.8 \mathrm{vs.} 4$ months) may explain the slightly lower achievement of LDL-C goal in our study. In the first DYSIS study performed in 2008-2009, 15.3\% of the 1470 patients with CAD enrolled in France achieved the LDL-C goal $<70 \mathrm{mg} / \mathrm{dL}$ [15]. In the recent International Cholesterol Management Practice Study (ICLPS) conducted in 18 countries outside Western Europe, the USA and Canada, 28.5\% of the 4882 patients with very high risk had LDL-C $<70 \mathrm{mg} / \mathrm{dL}$ [13]. Overall, these results indicate that lipid control in very high-risk patients remains insufficient despite the availability of LLT. Even in Western countries, the achievement of LDL-C goals remains suboptimal [14].

LLT before the index cardiac event was reported in $39.4 \%$ of patients. In the subgroup of patients without LLT prior to the index cardiac event, LLT was more frequently intensified after the index cardiac event $(95.3 \%$ vs. $45.4 \%)$, as expected. In these patients, the LDL-C goal was achieved more frequently than in patients with prior LLT ( $45.4 \%$ vs. $35.7 \%)$. Comparable results were obtained in DYSIS II Europe: 4 months after hospitalization for ACS, LDL-C levels $<70 \mathrm{mg} / \mathrm{dL}$ were achieved in $41.5 \%$ and $30.9 \%$ of patients without 
LLT or with LLT prior to ACS, respectively [12]. Presumably, regular refills of the same prescription or experience with previous adverse events lead to maintenance of the same dose in patients with previous LLT. On the other hand, patients who have never been on long-term therapy seem to be more willing to intensify it, thus achieving better LDL-C control rates.

Although only $41.7 \%$ of patients achieved LDL-C goals in our study, $42.8 \%$ of cardiologists were very satisfied and $29.8 \%$ were satisfied with the response to therapy. Significant improvement in LDL-C without achieving the goal is a possible explanation for these satisfaction rates, as well as considering patients "close to goal" as an acceptable result. When cardiologists were moderately satisfied/dissatisfied, the main reasons were not achieving objective and ineffective treatment. Treatment intolerance and poor compliance were less frequently reported.

This study has the limitations of an observational study. In addition, it was performed in France and its generalization to other countries is uncertain. Some data were missing, including LDL-C values before the index cardiovascular event, and, to a lesser extent, at study inclusion (only one lipid work-up after the index cardiac event was mandatory). Participating cardiologists were randomly selected throughout the French metropolitan territory and were asked to enroll patients consecutively. However, not all French departments were represented and some unknown biases remain possible. Therefore, the cohort could not be fully representative of the French population at very high cardiovascular risk treated for secondary prevention of CAD. Two thirds of the patients had already been followed by the study investigator before the index cardiac event for a mean duration of 8.1 years. Thus, this population appeared to be rather medically privileged and the estimate of the rate of achievement of the LDL-C goal in the general population was probably overestimated. Another limitation of the study is the absence of detailed analysis of LLT, such as the achievement of LDL-C according to monotherapy, non-statin LLT or combination.

\section{Conclusions}

These real-world results suggest that lipid control in very high-risk patients remains insufficient. More than half of the patients did not achieve the LDL-C goals. Prevention of cardiovascular events in these very high-risk patients could be further improved by better education and more intensive LLT.

Author Contributions: Conceptualization, J.F.; Investigation, J.F., F.R., M.F., P.J., D.A., F.B. and N.D.; Methodology, J.F., F.R., M.F., P.J., D.A., F.B. and N.D.; Supervision, J.F.; Writing一original draft, J.F.; Writing-review and editing, J.F., F.R., M.F., P.J., D.A., F.B. and N.D. All authors have read and agreed to the published version of the manuscript.

Funding: The study was funded by Amgen.

Institutional Review Board Statement: The study conformed to the principles of the Declaration of Helsinki and Good Clinical Practice Guidelines. It was approved by the Ethics Committee "CPP NORD-OUEST II" (ID-RCB: 2017-A00280-53).

Informed Consent Statement: This observational study did not change the physicians' relationship with the patients and the physicians remained free to continue their usual practice. Patients were informed of the study objectives and medical data processing.

Data Availability Statement: Data are available from the corresponding author upon reasonable request.

Acknowledgments: We thank C2R (Paris, France) for its contribution for conducting this study and Francis BEAUVAIS (Scientific and Medical Writing, Viroflay, France) for medical writing and editorial assistance with financial support from Amgen.

Conflicts of Interest: J. Ferrières has received consulting fees from Amgen, Akcea, Boehringer, Sanofi and Servier. F. Roubille has received consulting fees from Abbott, Air Liquide, Amgen, AstraZeneca, Bayer, Boehringer, Medtronic, Novonordisk, Pfizer, Sanofi, Servier and Zoll, and research grants from AstraZeneca. M. Farnier has received consulting fees from Abbott, Amarin, Amgen, AstraZeneca, Austell, Merck, Mylan, Pfizer, Sanofi and Servier. P. Jourdain has nothing to declare. D. Angoulvant 
has received consulting fees from Amgen, Alnylam, Astra Zeneca, Bayer, Boehringer, BMS, Novartis, Novo Nordisk, Pfizer, Sanofi and Servier. F. Boccara has received consulting fees from Amgen, Gilead, MSD, Sanofi, Servier and ViiV Healthcare. N. Danchin reports having received grants, speaking fees, consulting fees or non-financial support from Amgen, AstraZeneca, Bayer, BMS, Boehringer-Ingelheim, Intercept, MSD, Novo-Nordisk, Pfizer, Sanofi, Servier, UCB and Vifor.

\section{References}

1. Boren, J.; Chapman, M.J.; Krauss, R.M.; Packard, C.J.; Bentzon, J.F.; Binder, C.J.; Daemen, M.J.; Demer, L.L.; Hegele, R.A.; Nicholls, S.J.; et al. Low-density lipoproteins cause atherosclerotic cardiovascular disease: Pathophysiological, genetic, and therapeutic insights: A consensus statement from the European Atherosclerosis Society Consensus Panel. Eur. Heart J. 2020, 41, $2313-2330$. [CrossRef]

2. Raygor, V.; Khera, A. New recommendations and revised concepts in recent guidelines on the management of dyslipidemias to prevent cardiovascular disease: The 2018 ACC/AHA and 2019 ESC/EAS guidelines. Curr. Cardiol. Rep. 2020, 22, 87. [CrossRef] [PubMed]

3. Ference, B.A.; Ginsberg, H.N.; Graham, I.; Ray, K.K.; Packard, C.J.; Bruckert, E.; Hegele, R.A.; Krauss, R.M.; Raal, F.J.; Schunkert, H.; et al. Low-density lipoproteins cause atherosclerotic cardiovascular disease. 1. Evidence from genetic, epidemiologic, and clinical studies. A consensus statement from the European Atherosclerosis Society Consensus Panel. Eur. Heart J. 2017, 38, 2459-2472. [CrossRef] [PubMed]

4. $\quad$ Baigent, C.; Keech, A.; Kearney, P.M.; Blackwell, L.; Buck, G.; Pollicino, C.; Kirby, A.; Sourjina, T.; Peto, R.; Collins, R.; et al. Efficacy and safety of cholesterol-lowering treatment: Prospective meta-analysis of data from 90,056 participants in 14 randomised trials of statins. Lancet 2005, 366, 1267-1278. [PubMed]

5. Piepoli, M.F.; Hoes, A.W.; Agewall, S.; Albus, C.; Brotons, C.; Catapano, A.L.; Cooney, M.T.; Corra, U.; Cosyns, B.; Deaton, C.; et al. 2016 European Guidelines on cardiovascular disease prevention in clinical practice: The Sixth Joint Task Force of the European Society of Cardiology and Other Societies on Cardiovascular Disease Prevention in Clinical Practice (constituted by representatives of 10 societies and by invited experts) Developed with the special contribution of the European Association for Cardiovascular Prevention \& Rehabilitation (EACPR). Eur. Heart J. 2016, 37, 2315-2381. [PubMed]

6. Catapano, A.L.; Graham, I.; De Backer, G.; Wiklund, O.; Chapman, M.J.; Drexel, H.; Hoes, A.W.; Jennings, C.S.; Landmesser, U.; Pedersen, T.R.; et al. 2016 ESC/EAS Guidelines for the management of dyslipidaemias. Eur. Heart. J. 2016, 37, $2999-3058$. [CrossRef]

7. Mach, F.; Baigent, C.; Catapano, A.L.; Koskinas, K.C.; Casula, M.; Badimon, L.; Chapman, M.J.; De Backer, G.G.; Delgado, V.; Ference, B.A.; et al. 2019 ESC/EAS Guidelines for the management of dyslipidaemias: Lipid modification to reduce cardiovascular risk. Eur. Heart J. 2020, 41, 111-188. [CrossRef]

8. Grundy, S.M.; Stone, N.J.; Bailey, A.L.; Beam, C.; Birtcher, K.K.; Blumenthal, R.S.; Braun, L.T.; de Ferranti, S.; Faiella-Tommasino, J.; Forman, D.E.; et al. 2018 AHA/ACC/AACVPR/AAPA/ABC/ACPM/ADA/AGS/APhA/ASPC/NLA/PCNA Guideline on the management of blood cholesterol: Executive summary: A report of the American College of Cardiology/American Heart Association Task Force on clinical practice guidelines. Circulation 2019, 139, e1046-e1081. [PubMed]

9. Kotseva, K.; Wood, D.; De Bacquer, D.; De Backer, G.; Ryden, L.; Jennings, C.; Gyberg, V.; Amouyel, P.; Bruthans, J.; Castro Conde, A.; et al. EUROASPIRE IV: A European Society of Cardiology survey on the lifestyle, risk factor and therapeutic management of coronary patients from 24 European countries. Eur. J. Prev. Cardiol. 2016, 23, 636-648. [CrossRef] [PubMed]

10. Gitt, A.K.; Lautsch, D.; Ferrieres, J.; Kastelein, J.; Drexel, H.; Horack, M.; Brudi, P.; Vanneste, B.; Bramlage, P.; Chazelle, F.; et al. Contemporary data on low-density lipoprotein cholesterol target value attainment and distance to target in a cohort of 57,885 statin-treated patients by country and region across the world. Data Brief 2016, 9, 616-620. [CrossRef] [PubMed]

11. Gitt, A.K.; Lautsch, D.; Ferrieres, J.; Kastelein, J.; Drexel, H.; Horack, M.; Brudi, P.; Vanneste, B.; Bramlage, P.; Chazelle, F.; et al. Low-density lipoprotein cholesterol in a global cohort of 57,885 statin-treated patients. Atherosclerosis 2016, 255, 200-209. [CrossRef] [PubMed]

12. Ferrieres, J.; De Ferrari, G.M.; Hermans, M.P.; Elisaf, M.; Toth, P.P.; Horack, M.; Brudi, P.; Lautsch, D.; Bash, L.D.; Baxter, C.A.; et al. Predictors of LDL-cholesterol target value attainment differ in acute and chronic coronary heart disease patients: Results from DYSIS II Europe. Eur. J. Prev. Cardiol. 2018, 25, 1966-1976. [CrossRef] [PubMed]

13. Danchin, N.; Almahmeed, W.; Al-Rasadi, K.; Azuri, J.; Berrah, A.; Cuneo, C.A.; Karpov, Y.; Kaul, U.; Kayikcioglu, M.; Mitchenko, O.; et al. Achievement of low-density lipoprotein cholesterol goals in 18 countries outside Western Europe: The International ChoLesterol management Practice STUDY (ICLPS). Eur. J. Prev. Cardiol. 2018, 25, 1087-1094. [CrossRef] [PubMed]

14. Ferrieres, J.; Rouyer, M.V.; Lautsch, D.; Ashton, V.; Ambegaonkar, B.M.; Brudi, P.; Gitt, A.K. Dyslipidemia international study, I.I.F.S.G. suboptimal achievement of low-density lipoprotein cholesterol targets in French patients with coronary heart disease. Contemporary data from the DYSIS II ACS/CHD study. Arch. Cardiovasc. Dis. 2017, 110, 167-178. [CrossRef] [PubMed]

15. Ferrieres, J.; Rouyer, M.V.; Lautsch, D.; Ambegaonkar, B.M.; Horack, M.; Brudi, P.; Gitt, A.K.; Dyslipidemia International Study (DYSIS) and DYSIS II Study Group. Improvement in achievement of lipid targets in France: Comparison of data from coronary patients in the DYSIS and DYSIS II studies. Int. J. Cardiol. 2016, 222, 793-794. [CrossRef] [PubMed] 